\title{
Positive end-expiratory pressure and lung compliance: effect on delivered tidal volume
}

The effects of positive end-expiratory pressure (PEEP) and lung compliance $\left(C_{L}\right)$ on delivered tidal volume $\left(V_{\text {Tdel }}\right)$ and ventilator output were evaluated in the following anaesthesia machine/ ventilator systems: Narkomed III with a Model $A V-E$ ventilator (III/AV-E system) and an Ohmeda Modulus II with either a 7810 anaesthesia ventilator (II/7810 system) or a Model 7000 anaesthesia ventilator (II/7000 system). With a standard circle anaesthesia breathing circuit connected to a test lung simulating $C_{L}$ gas flow was measured and integrated over time at each combination of $V_{T}$ settings $\left(V_{T s e t}\right), 500 \mathrm{ml}$ or $1000 \mathrm{ml} ; C_{L}$ settings, 0.15 to $0.01 \mathrm{~L} \cdot \mathrm{cm} \mathrm{H}_{2} \mathrm{O}^{-1}$ decreased incrementally; and PEEP settings, $\mathrm{O}$ to $30 \mathrm{~cm} \mathrm{H}_{2} \mathrm{O}$ increased in $5-\mathrm{cm} \mathrm{H}_{2} \mathrm{O}$ increments. The integral of gas flow at the $Y$-piece of the breathing circuit was recorded as $V_{\text {Tdel }}$ and at the output of the ventilator bellows as ventilator output. As $C_{L}$ decreased to 0.01 $\mathrm{L} \cdot \mathrm{cm} \mathrm{H}_{2} \mathrm{O}^{-1}$ and PEEP increased to $30 \mathrm{~cm} \mathrm{H}_{2} \mathrm{O}$, at $V_{7 \mathrm{set}}$ of $500 \mathrm{ml}$ and $1000 \mathrm{ml}$, respective $V_{\text {Tdel }}$ decreased linearly to $251 \pm 6 \mathrm{ml}$ and $542 \pm 7$ with the III/AV-E, $201 \pm 5$ and $439 \pm 5$, with the $I I / 7810$, and $181 \pm 4$ and $433 \pm 7 \mathrm{ml}$ with the $I / 7000$ ( $P<0.05$ among the three systems). Loss in $V_{\text {Tdel }}$ due to PEEP alone, which increased only slightly when $V_{T s e t}$ was increased, accounted for an increasingly greater percentage of $V_{T s e t}$ as it was decreased, which was less pronounced with low $C_{L}$. Effects of PEEP and $C_{L}$ on ventilator output were similar to those on $V_{T d e l}$ but of lesser magnitude. During PEEP, $V_{T s e t}$ must be increased to compensate for loss in $V_{T d e l}$ and expired $V_{T}$ must be monitored to prevent hypoventilation.

\section{Key words}

ANAESTHESIA: equipment;

EQUIPMENT: ventilators;

LUNG: tidal volume.

From the Department of Anesthesiology, University of Florida College of Medicine, Gainesville, Florida. Dr. Pan is Currently Associate Professor of Anesthesiology at Medical College of Virginia, Virginia Commonwealth University, Richmond, Virginia.

Address correspondence to: Attn: Editorial Office, Dr. Pan,

Department of Anesthesiology, University of Florida College of Medicine, P.O. Box 100254, Gainesville, FL 32610-0254.

Accepted for publication 19th May, 1995.
Les effets de la pression expiratoire positive (PEEP) et de la compliance pulmonaire $\left(C_{D}\right)$ sur le volume courant généré $\left(V_{T d e l}\right)$ et le débit du ventilateur mécanique sont évalués sur les appareils d'anesthésie équipés d'un ventilateur: Narkomed III avec un ventilateur $A V-E$ (système III/AV-E) et un appareil d'anesthésie Ohmeda Modulus II équipé d'un ventilateur d'anesthésie 7810 (système 11/7810) ou d'un ventilateur d'anesthésie 7000 (système 11/7000). Avec une circuit standard avec absorption branché sur un poumon arificiel simulant la $C_{L}$ le débit gazeux et mesuré et intégré par rapport au temps pour chacune des combinaisons de réglage du $V_{T}\left(V_{T s e t}\right), 500 \mathrm{ml}$ ou $1000 \mathrm{ml}$; de réglage de la $\mathrm{C}_{\mathrm{L}}$ de 0,15 à $0,01 \mathrm{~L} \cdot \mathrm{cm} \mathrm{H} \mathrm{H}_{2} \mathrm{O}^{-1}$ diminuée par plateau; réglage du PEEP augmenté par plateau de $\mathrm{O}$ à $30 \mathrm{~cm} \mathrm{H}_{2} \mathrm{O}$. Lorsque que la $\mathrm{C}_{L}$ à $0,01 \mathrm{~L} \cdot \mathrm{cm} \mathrm{H}_{2} \mathrm{O}^{-1}$ et que le PEEP augmente à $30 \mathrm{~cm} \mathrm{H}_{2} \mathrm{O}$, aux $V_{\text {Tset }}$ de 500 $\mathrm{ml}$ et $1000 \mathrm{ml}$, le $V_{T d e l}$ diminue linéairement à $251 \pm 6 \mathrm{ml}$ et $542 \pm 7 \mathrm{ml}$ avec le $I I I / A V-E$, à $201 \pm 5$ et $439 \pm 5$ avec le $I I / 7810$, et à $181 \pm 4$ et $433 \pm 7 \mathrm{ml}$ avec le $I / 7000$ (P $<0,05$ entre les trois systèmes.) La perte de $V_{\text {Tdel }}$ due au PEEP seul, qui n'augmente que légèrement quand le $V_{\text {Tset }}$ est augmenté, explique un plus grand pourcentage de $V_{T_{\text {set }}}$ quand celui-ci est diminué, ce qui est moins prononcé quand la $C_{L}$ est basse. Les effets du PEEP et de la $C_{L}$ sur le débit du ventilateur sont les mêmes que ceux notés sur le $V_{\text {Tdeb }}$ mais de moindre importance. Pendant le PEEP, $V_{T s e t}$ doit être augmenté pour compenser pour la perte de $V_{T d e t}$ Le $V_{T}$ expiré doit être monitoré pour prévenir l'hypoventilation.

For controlled mechanical ventilation of anaesthetized patients during surgery, an anaesthesia machine is commonly connected in sequence with an anaesthesia ventilator. Patients with respiratory failure who undergo surgery may require high levels of minute ventilation, peak inspiratory airway pressure, and positive endexpiratory pressure (PEEP). The tidal volume delivered to the patient $\left(V_{\text {Tdel }}\right)$ is usually determined not only by the tidal volume setting on the ventilator $\left(\mathrm{V}_{\mathrm{Tse}}\right)$, but also by the fresh gas flow rate, the compliance of breathing circuit tubing, and the compressibility of gas. ${ }^{1-4}$ The greater the peak inspiratory pressure, the greater is the compression of delivered gas volume and the more the 


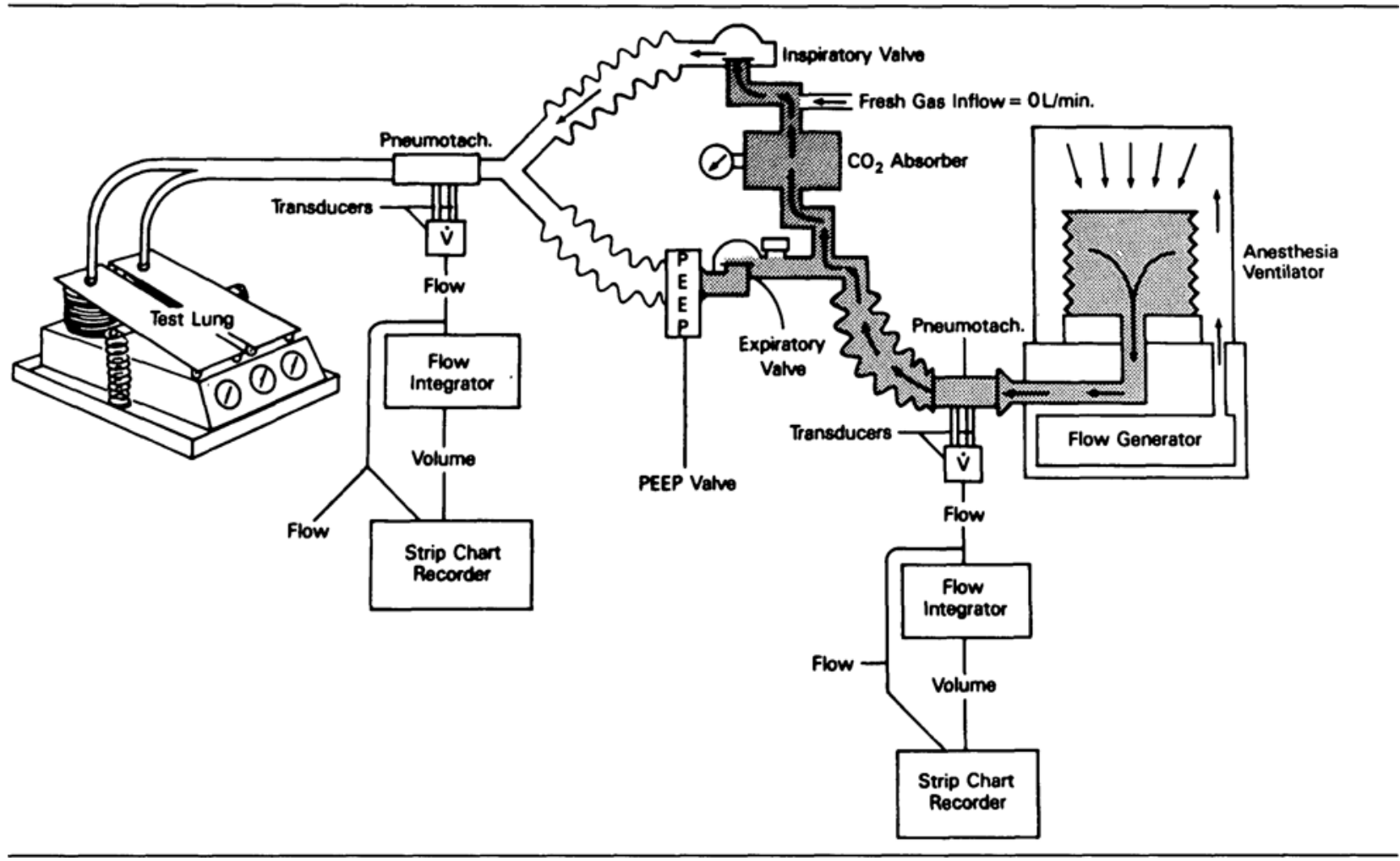

FIGURE 1 Diagram of experimental arrangement. The application of PEEP requires additional gas compression within the volume enclosed by the ventilator bellows, the $\mathrm{CO}_{2}$ absorber, the inspiratory valve, and the PEEP valve to increase pressure from ambient (shaded area).

circuit tubing is distended; these effects decrease $V_{\text {Tdel. }}$ Further, while it improves oxygenation in some patients, ${ }^{5}$ PEEP may also affect ventilator performance and, thus, decrease $V_{\text {Tdel. }}$. This study was undertaken to quantify the effect of PEEP on $V_{\text {Tdel }}$ at different levels of lung compliance $\left(C_{L}\right)$ during mechanical ventilation with three commonly used anaesthesia machine/ventilator systems.

\section{Methods}

The following three commonly used anaesthesia machine/ventilator systems were evaluated:

- III/AV-E: A Narkomed III anaesthesia machine (North American Dräger) with the vaporizer turned off, an AV-E ventilator (North American Dräger, Telford , PA) and carbon dioxide absorber, $90 \mathrm{~cm}$ of $22-$ mm corrugated tubing connecting ventilator and $\mathrm{ab}$ sorber, and a disposable polyethylene circle breathing circuit (Intertech/Ohio, Bannockburn, IL).

- II/7810: A Modulus II anaesthesia machine (Ohmeda, Madison, WI) with the vaporizer turned off, a model 7810 ventilator (Ohmeda), a carbon dioxide absorber (GMS, Ohmeda), and a disposable polyethylene circle breathing circuit (Intertech/Ohio).

- II/7000: The same configuration as the II/7810 but with a model 7000 ventilator (Ohmeda).
For each system, a series of spring-loaded PEEP valves (Vital Signs, Totowa, NJ), in sequence from 5 to $30 \mathrm{~cm}$ $\mathrm{H}_{2} \mathrm{O}$, were placed at the junction of the expiratory valve and the expiratory limb of the circle breathing circuit (Figure 1). A pneumotachograph (model \#2, Gleisch, Blue Bell, PA) and a differential pressure transducer (Statham-Gould, Anaheim, CA) were placed at the output of the ventilator bellows to measure ventilator output and at the connection of the Y-piece to an adult test lung (Michigan Instruments, Grand Rapids, MI) to measure $\mathrm{V}_{\text {Tdel }}$ (Figure 1). The adult test lung was used to simulate $C_{L}$. Flow signals were integrated (Grass Medical Instruments, Quincy, MA) to measure volume. The pneumotachograph was calibrated under ambient temperature and pressure with a calibration syringe (model \#021156, WE Collins, Braintree, MA). The differential pressure transducer was calibrated against a water manometer (Wescor). The anaesthesia machine/ventilator systems were all tested (including for leaks) and calibrated according to manufacturers' recommendations before the study.

For the experiment, the anaesthesia machine and ventilator were set as follows: fresh gas flow of $0 \mathrm{~L} \cdot \mathrm{min}^{-1}$, inspiratory-to-expiratory ratio of $1: 2$, and respiratory rate of 10 breaths $\cdot \min ^{-1}$. Before data collection, ventilators 
were calibrated at $\mathrm{C}_{\mathrm{L}}$ of $0.15 \mathrm{~L} \cdot \mathrm{cm} \mathrm{H} \mathrm{H}^{-1}$, airway resistance of $2 \mathrm{~cm} \cdot \mathrm{L}^{-1} \cdot \mathrm{sec}^{-1}$, PEEP of 0 , and $V_{\text {Tset }}$ of 500 and $1000 \mathrm{ml}$. These settings were used as the reference point of all corresponding comparisons of $V_{\text {Tdes }}$ and ventilator output at the two levels of $V_{\text {Tset }}$ with different combinations of PEEP and $\mathrm{C}_{\mathrm{L}}$ as follows: PEEP was increased from 0 to $30 \mathrm{~cm} \mathrm{H}_{2} \mathrm{O}$ in $5-\mathrm{cm}_{2} \mathrm{O}$ increments and $\mathrm{C}_{\mathrm{L}}$ was decreased from 0.15 to $0.05,0.03$, 0.02 , and $0.01 \mathrm{~L} \cdot \mathrm{cm} \mathrm{H}_{2} \mathrm{O}^{-1}$, consecutively. At each combination of PEEP, $\mathrm{C}_{\mathrm{L}}$, and $\mathrm{V}_{\text {Tset, }}$ measurements were repeated five times.

Unpaired $t$ test with Bonferroni correction and analysis of variance (ANOVA) with post hoc Tukey testing was used for statistical comparison of $V_{\text {Tdel }}$ and ventilator output among the three systems for each combination of PEEP, $\mathrm{C}_{\mathrm{L}}$, and $\mathrm{V}_{\mathrm{Tser}}$. Two-way ANOVA with post hoc Tukey testing was used to compare $V_{\text {Tdel }}$ and ventilator output within each anaesthesia ventilator system at different settings of PEEP and $C_{L}$. The decrease in $V_{\text {Tdel }}$ due to PEEP alone ( $\left.V_{\text {TPEEPloss }}\right)$ was compared between two different levels of $V_{\text {Tset }}$ for each of the anaesthesia ventilators by ANOVA and post hoc Tukey testing. $P$ $<0.05$ was considered significant.

\section{Results}

All anaesthesia machine-ventilator systems used in the study were well within acceptable operating specifications and had no leaks. The effects of PEEP and $C_{L}$ on $V_{\text {Tdel }}$ were similar among the three anaesthesia machine/ventilator systems at either $V_{\text {Tset: }} V_{\text {Tdel }}$ was always $\left\langle V_{\text {Tset }}\right.$ The difference (as a percentage of $V_{\text {Tsec }}$ ) was always greater at $V_{\text {Tset }}$ of $500 \mathrm{ml}$ than $1000 \mathrm{ml}$ (Figures 2 and 3 ), and the effect was most prominent with the II/7000 and least for the III/AV-E system.

Merely decreasing the simulated $C_{L}$ from the reference value of 0.15 to $0.05 \mathrm{~L} \cdot \mathrm{cm} \mathrm{H}_{2} \mathrm{O}^{-1}$ without PEEP decreased $V_{\text {Tdel }}$ from $V_{\text {Tset }}$ of $500 \mathrm{ml}$ to $451 \pm 6 \mathrm{ml}$ with the III/AV-E, to $450 \pm 4 \mathrm{ml}$ with the II/7810, and to $412 \pm 5 \mathrm{ml}$ with the $\mathrm{I} / 7000(P<0.05$ comparing the II/ 7000 with the III/AV-E or the II/7810) and from $V_{\text {Tset }}$ of $1000 \mathrm{ml}$ to, respectively, $900 \pm 9,872 \pm 7$, and 842 $\pm 9 \mathrm{ml}(P<0.05$ among the three systems). With simulated $\mathrm{C}_{\mathrm{L}}$ remaining at $0.05 \mathrm{~L} \cdot \mathrm{cm} \mathrm{H}_{2} \mathrm{O}^{-1}$ as PEEP was increased from 0 to $30 \mathrm{~cm} \mathrm{H}_{2} \mathrm{O}, \mathrm{V}_{\text {Tdel }}$ further decreased from $\mathrm{V}_{\text {Tset }}$ of $500 \mathrm{ml}$ to $340 \pm 4 \mathrm{ml}$ with the III/AV$\mathrm{E}$, to $303 \pm 4 \mathrm{ml}$ with the $\mathrm{II} / 7810$, and to $280 \pm 6$ $\mathrm{ml}$ with the II/ 7000 ( $P<0.05$ among the three systems), and from $V_{\text {Tset }}$ of $1000 \mathrm{ml}$, respectively, to $782 \pm 9,704$ \pm 9 , and $693 \pm 7 \mathrm{ml}(P<0.05$ comparing the III/ AV-E with the II/7810 or the II/7000) (Figures 2 and 3).

Decreasing the simulated $C_{L}$ from the reference setting of 0.15 to $0.01 \mathrm{~L} \cdot \mathrm{cm} \mathrm{H}_{2} \mathrm{O}^{-1}$ without PEEP decreased

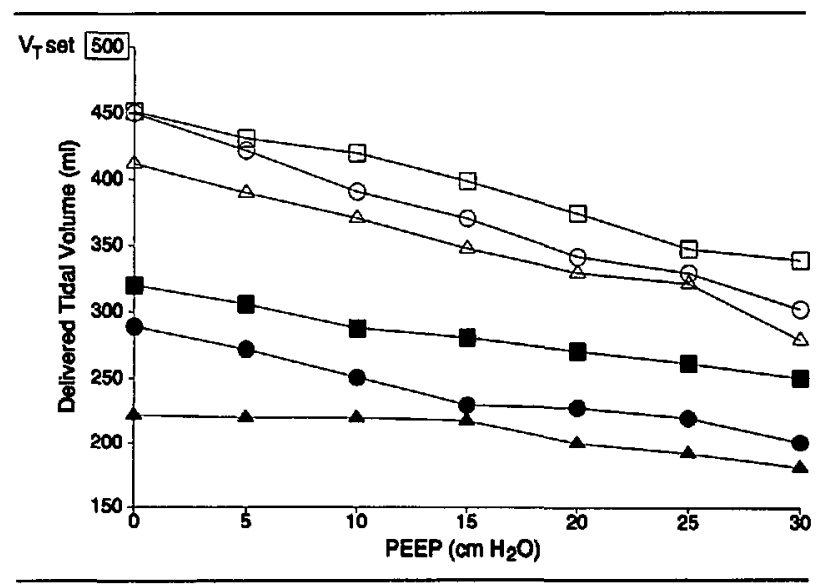

FIGURE 2 Delivered tidal volume (mean) at lung compliances of $0.05 \mathrm{~L} \cdot \mathrm{cm} \mathrm{H}_{2} \mathrm{O}^{-1}$ (open symbols) and $0.01 \mathrm{~L} \cdot \mathrm{cm} \mathrm{H}_{2} \mathrm{O}^{-1}$ (solid symbols) during positive end expiratory pressure (PEEP) and ventilation with a tidal volume setting $\left(V_{\text {Tsev }}\right)$ of $500 \mathrm{ml}$ on the following three anaesthesia machine/ventilator systems: Narkomed III and an AV-E ventilator (squares) and a Modulus II with either a 7810 ventilator (circles) or a 7000 ventilator (triangles). The SD for all measurements never exceeded 11.

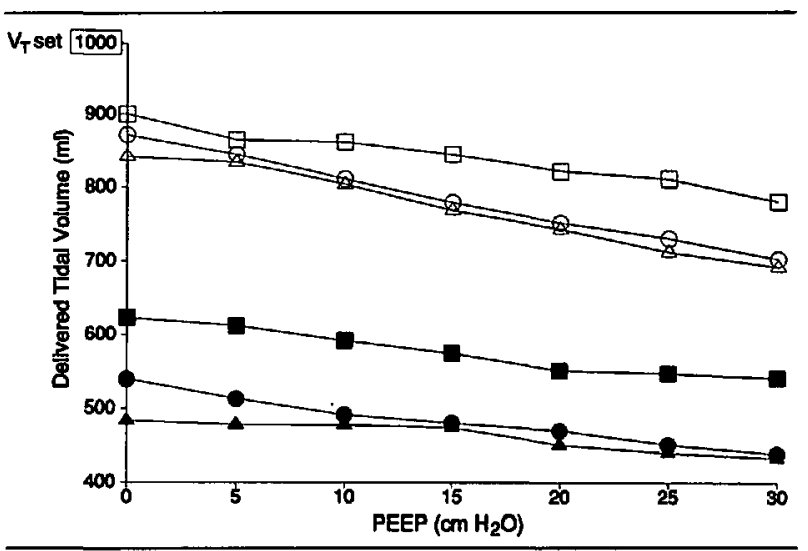

FIGURE 3 Delivered tidal volume (mean) at lung compliances of $0.05 \mathrm{~L} \cdot \mathrm{cm} \mathrm{H}_{2}{ }^{-1}$ (open symbols) and $0.01 \mathrm{~L} \cdot \mathrm{cm} \mathrm{H}_{2}{ }^{-1}$ (solid symbols) during positive end expiratory pressure (PEEP) and ventilation with a tidal volume setting $\left(\mathrm{V}_{\mathrm{Tset}}\right)$ of $1000 \mathrm{ml}$ on the following three anaesthesia machine/ventilator systems: Narkomed III and an AV-E ventilator (squares) and a Modulus II with either a 7810 ventilator (circles) or a 7000 ventilator (triangles). The $S D$ for all measurements never exceeded 11 .

$\mathrm{V}_{\text {Tdel }}$ from $\mathrm{V}_{\text {Tset }}$ of $500 \mathrm{ml}$ to $320 \pm 4 \mathrm{ml}$ with the III/AV-E, to $289 \pm 5 \mathrm{ml}$ with the II/7810, and to 222 $\pm 5 \mathrm{ml}$ with the II/7000 ( $P<0.05$ among the three systems) and from $V_{\text {Tset }}$ of $1000 \mathrm{ml}$ to, respectively, 623 $\pm 8,540 \pm 11$, and $484 \pm 7 \mathrm{ml}(P<0.05$ among the three systems). With $\mathrm{C}_{\mathrm{L}}$ remaining at $0.01 \mathrm{~L} \cdot \mathrm{cm} \mathrm{H} \mathrm{H}_{2} \mathrm{O}^{-1}$ as PEEP was increased from 0 to $30 \mathrm{~cm} \mathrm{H}_{2} \mathrm{O}, \mathrm{V}_{\text {Tdel }}$ further decreased from $V_{\text {Tset }}$ of $500 \mathrm{ml}$ to $251 \pm 6 \mathrm{ml}$ with III/AV-E, to $201 \pm 5$ with the II/7810, and to $181 \pm$ 


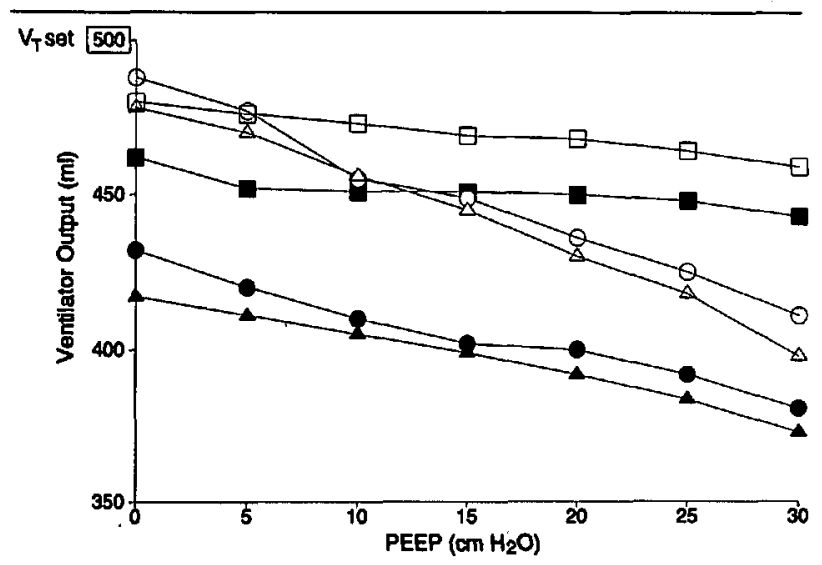

FIGURE 4 Ventilator output (mean) at lung compliances of 0.05 $\mathrm{L} \cdot \mathrm{cm} \mathrm{H}{ }_{2}^{-1}$ (open symbols) and $0.01 \mathrm{~L} \cdot \mathrm{cm} \mathrm{H}_{2}{ }^{-1}$ (solid symbols) during positive end-expiratory pressure (PEEP) and ventilation with a tidal volume setting $\left(V_{\text {Tset }}\right)$ of $500 \mathrm{ml}$ on the following three anaesthesia machine/ventilator systems: Narkomed III and an AV-E ventilator (squares) and a Modulus II with either a 7810 ventilator (circles) or a 7000 ventilator (triangles). The SD for all measurements never exceeded 11 .

4 with the II/7000 and from $\mathrm{V}_{\text {Tset }}$ of $1000 \mathrm{ml}$ to, respectively, $542 \pm 7,439 \pm 5$, and $433 \pm 7 \mathrm{ml}(P<$ 0.05 among the three systems) (Figures 4 and 5 ). The $V_{\text {TPEEPloss }}$ increased only slightly but significantly when $V_{\text {Tset }}$ was increased from 500 to $1000 \mathrm{ml}$ (Table), thus, the decrease $\left(V_{\text {TPEEPloss }}\right)$ as a percentage of $V_{\text {Tset }}$ was greater at $V_{\text {Tset }}$ of 500 than of $1000 \mathrm{ml}$.

The effect of PEEP and $C_{L}$ on ventilator output was similar to that on $V_{\text {Tdel, }}$, but of lesser magnitude (Figures 4 and 5). Compared with the ventilator output with the II/ 7810 and II/7000, that with the III/AV-E was affected least $(P<0.05)$. When $\mathrm{C}_{\mathrm{L}}$ was decreased from 0.15 to $0.01 \mathrm{~L} \cdot \mathrm{cm} \mathrm{H} \mathrm{O}^{-1}$, ventilator output with the III/AV$\mathrm{E}$ decreased less than $8 \%$ at $\mathrm{V}_{\text {Tset }}$ of $500 \mathrm{ml}$ and less than $6 \%$ at a $\mathrm{V}_{\text {Tset }}$ of $1000 \mathrm{ml}$.

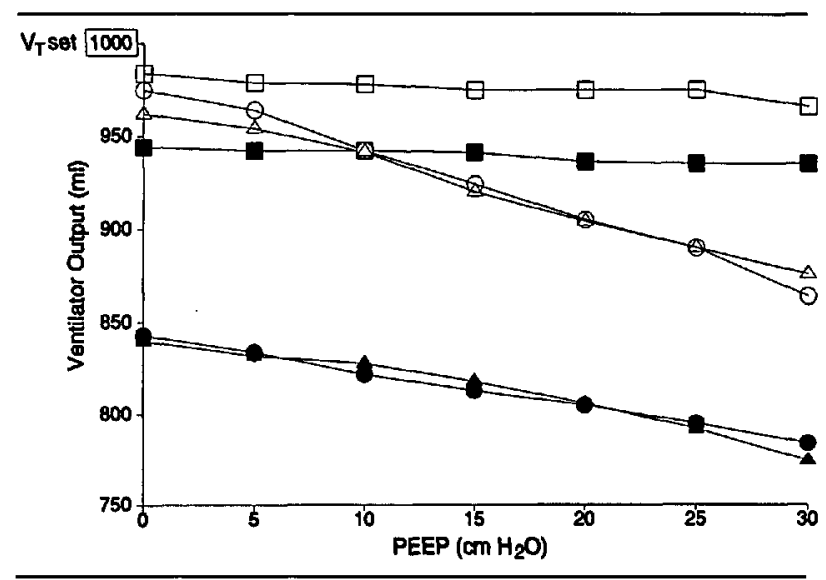

FIGURE 5 Ventilator output (mean) at lung compliances of 0.05 $\mathrm{L} \cdot \mathrm{cm} \mathrm{H}_{2}{ }^{-1}$ (open symbols) and $0.01 \mathrm{~L} \cdot \mathrm{cm} \mathrm{H}_{2}^{-1}$ (solid symbols) during positive end-expiratory pressure (PEEP) and ventilation with a tidal volume setting ( $V_{\text {Tset }}$ ) of $1000 \mathrm{ml}$ on the following three anaesthesia machine/ventilator systems: Narkomed III and an AV-E ventilator (squares) and a Modulus II with either a 7810 ventilator (circles) or a 7000 ventilator (triangles). The SD for all measurements never exceeded 11.

\section{Discussion}

We measured ventilator output at the ventilator bellows in order to evaluate the portion of change in $V_{\text {Tdel }}$ due solely to ventilator performance, that is, the portion of $V_{\text {Tdel }}$ independent of the breathing circuit and anaesthesia machine. The effect of PEEP on $V_{\text {Tdel }}$ results from gas compression of the space within the ventilator bellows, the inspiratory valve, and the PEEP valve (Figure 1, shaded area), which is required to increase ambient pressure. The $V_{\text {Tdel }}$ can be derived from the following equation. ${ }^{1,5,6}$

$V_{\text {Tdel }}=V_{\text {Tset }}+$ fresh gas flow rate $\cdot$ inspiratory time

$$
-V_{\text {TPEEPloss }}-V_{T\left(C+C_{\mathrm{L}}\right. \text { loss }}
$$

where $V_{T\left(C_{L}+C\right) \text { loss }}$ is the loss due solely to $C_{L}$ and com-

TABLE Loss of delivered tidal volume caused by positive end expiratory pressure alone (PEEP) at different simulated lung compliances and different tidal volume settings $\left(V_{T s e}\right)$ on three anaesthesia machine/ ventilator systems

\begin{tabular}{|c|c|c|c|c|}
\hline \multirow{3}{*}{$\begin{array}{l}\text { Anaesthesia/machine } \\
\text { ventilator system }\end{array}$} & \multicolumn{4}{|c|}{ Loss of delivered $V_{T}(\mathrm{ml})$ caused only by PEEP of $30 \mathrm{~cm} \cdot \mathrm{H}_{2} \mathrm{O}^{-1}$} \\
\hline & \multicolumn{2}{|c|}{ Lung compliance of $0.05 \mathrm{~L} \cdot \mathrm{cm} \mathrm{H}_{2} \mathrm{O}^{-1}$} & \multicolumn{2}{|c|}{ Lung compliance of $0.01 \mathrm{~L} \cdot \mathrm{cm} \mathrm{H}_{2} \mathrm{O}^{-1}$} \\
\hline & $V_{T s e t}$ of $1000 \mathrm{ml}$ & $V_{\text {rset }}$ of $500 \mathrm{ml}$ & $V_{\text {Tset }}$ of $1000 \mathrm{ml}$ & $V_{T s e s}$ of $500 \mathrm{ml}$ \\
\hline Narkomed III/AV-E & $118 \pm 7$ & $111 \pm 4$ & $81 \pm 9$ & $69 \pm 2 *$ \\
\hline Modulus II/7810 & $168 \pm 7$ & $147 \pm 2^{*}$ & $101 \pm 8$ & $88 \pm 5^{*}$ \\
\hline Modulus II/7000 & $149 \pm 5$ & $132 \pm 4^{*}$ & $51 \pm 8$ & $41 \pm 2^{*}$ \\
\hline
\end{tabular}

Values are means $\pm S D$. PEEP of $30 \mathrm{~cm} \cdot \mathrm{H}_{2} \mathrm{O}$ represents the worst case.

$* P<0.05$ compared with $V_{\text {Tset }}$ of $1000 \mathrm{ml}$ at the same lung compliance. 
pression of circuit and gas. Fresh gas flow augments $\mathrm{V}_{\text {Tdel, }}{ }^{1}$ therefore, we used a fresh gas flow rate of 0 in this study. The equation can then be reduced to:

$\mathrm{V}_{\text {Tdel }}=\mathrm{V}_{\text {Tset }}-\mathrm{V}_{\text {TPEEPloss }}-\mathrm{V}_{\mathrm{T}\left(\mathrm{C}+\mathrm{C}_{\mathrm{L}} \text { loss }\right.}$.

Without PEEP, the total loss of $V_{T}$ results only from compression of the circuit and gas to increase pressure from the level at end-expiration to that at peak inspiration. A typical adult anaesthesia circle circuit with ventilator has a compression volume of 6 to $7 \mathrm{~L}$ and a compressibility of 6 to $12 \mathrm{ml} \cdot \mathrm{cm} \mathrm{H}_{2} \mathrm{O}^{-1}$. With the addition of PEEP, however, additional gas compression is required to increase pressure from ambient to PEEP within the space enclosed by the ventilator bellows, the $\mathrm{CO}_{2}$ absorber, the inspiratory valve, and the PEEP valve (Figure 1, shaded area).

Our results show that $V_{\text {TPEEPloss }}$ increased only slightly when $V_{\text {Tset }}$ was increased while $C_{L}$ remained constant (Table). Therefore, $V_{\text {TPEEPloss }}$ becomes a relatively greater percentage of $V_{\text {Tset }}$ when $V_{\text {Tset }}$ is lower, which supports others' findings. ${ }^{6}$ This study also confirms that PEEP alone decreases $V_{\text {Tdel }}$ much less with the higher $C_{L}$ typical of normal lungs than with the low $\mathrm{C}_{\mathrm{L}}$ as would occur in patients with stiff lungs. Even before PEEP is applied, lower $C_{L}$ alone already decreases $V_{\text {Tdel }}$. With low $C_{L}$, PEEP causes $V_{T d e l}$ to begin to decrease at the flatter portion of the compliance curve. Nevertheless, even though the $V_{\text {TPEEPloss }}$ is less with low $C_{L}$, the decrease is still substantial. Therefore, patients with respiratory failure who undergo surgery, those who are most in need of a precise $V_{\text {Tdel, }}$, are not likely to get it without proper adjustment of the ventilator, that is, without increasing $\mathrm{V}_{\text {Tdel. }}$.

In summary, adding PEEP to an anaesthesia breathing circuit decreases $V_{\text {Tdel, }}$ and the effect becomes increasingly greater as $V_{\text {Tset }}$ is decreased. Decreased $C_{L}$ mitigates the effect of PEEP on $V_{\text {Tdel }}$. As PEEP is added or $C_{L}$ is decreased or both occur simultaneously, expired $V_{T}$ must be monitored and $\mathrm{V}_{\text {Tset }}$ adjusted to compensate for loss of $V_{\text {Tdel }}$ and to prevent hypoventilation. Future anaesthesia machine/ventilator designs may be improved by adding a feedback mechanism to increase flow to the ventilator if measured $V_{\text {Tdel }}$ does not approximate $V_{\text {Tset, }}$ which would produce more reliable $V_{\text {Tdel }}$ over a wider range of clinical conditions.

\section{Acknowledgements}

This material was presented in part at the 1990 Annual Meeting of the American Society of Anesthesiologists, Las Vegas, Nevada, October 19-23, 1990. The authors thank Lynn Dirk of the Department of Anesthesiology, University of Florida for editing the manuscript.

\section{References}

1 Gravenstein N, Banner MJ, McLaughlin G. Tidal volume changes due to the interaction of anesthesia machine and anesthesia ventilator. J Clin Monit 1987; 3: 187-90.

2 Forbat $A F$, Her $C$. Correction for gas compression in mechanical ventilators. Anesth Analg 1980; 59: 488-93.

3 Robbins L, Crocker D, Smith RM. Tidal volume losses of volume-limited ventilators. Anesth Analg 1967; 46: 428-31.

4 Saklad M, Paliotta J. A nomogram for the correction of needed gases during artificial ventilation. Anesthesiology 1968; 29: 150-2.

5 Ashbaugh DG, Petty TL, Bigelow DB, Harris TM. Continuous positive-pressure breathing (CPPB) in adult respiratory distress syndrome. J Thorac Cardiovasc Surg 1969; 57: 31-41.

6 Elliott WR, Harris AE, Philip JH. Positive end-expiratory pressure: implications for tidal volume changes in anesthesia machine ventilation. J Clin Monit 1989; 5: 100-4.

7 Coté CJ, Petkau AJ, Ryan JF, Welch JP. Wasted ventilation measured in vitro with eight anesthetic circuits with and without inline humidification. Anesthesiology 1983; 59: 442-6. 